\title{
STRUCTURAL CHANGES OF NITROGEN FERRITE AFTER AGING IN TEMPERATURE INTERVAL UP TO $100^{\circ} \mathrm{C}$
}

\author{
Tatyana MECHKAROVA, Yaroslav ARGIROV, Daniela SPASOVA, \\ Aneliya STOYANOVA \\ Technical University of Varna, Bulgaria \\ e-mail: tatqna13@abv.bg
}

\begin{abstract}
This paper aims to determine the extent of aging of nitrogen ferrite at temperatures below $100{ }^{\circ} \mathrm{C}$ and the structural and strength changes that occur in the process. The tests are carried out on samples of technically pure iron (Armco). The specimens are pre-deformed by tension and re-crystallisation heating to achieve a large-grain ferrite structure. A large-grained structure has been chosen to more accurately track the change in micro-hardness of the individual grains during the aging process. Nitric ferrite results from gas carbonitriding and subsequent hardening. Upon hardening, the samples are stored in a refrigerator, and then the surface layer formed is removed through electrochemical corrosion. Afterwards, aging heat treatment at temperatures below $100{ }^{\circ} \mathrm{C}$ is undertaken. After the aging process, micro-hardness of the individual grains is examined and $X$-ray structural analysis is performed.
\end{abstract}

KEYWORDS: nitric ferrite, aging, gas carbonitriding, micro-hardness, X-ray structural analysis

\section{Introduction}

The aging tendency of nitric ferrite is recognized in literature [1-5]. This is caused by the high solubility of nitrogen in $\alpha$-Fe $(0.11 \%)$ at nitriding temperature and its change during the cooling process, reaching up to $0.04 \%$ at $20{ }^{\circ} \mathrm{C}$ [6-9]. Most of the research on the aging of nitric ferrite is undertaken at aging temperature of $100{ }^{\circ} \mathrm{C}$, at which much of the phase changes occur. These phase changes consist in the continuous release of iron nitrites of the type $\mathrm{Fe}_{16} \mathrm{~N}_{2}(\alpha)$ and $\mathrm{Fe}_{4} \mathrm{~N}\left(\gamma^{\prime}\right)$. The first $\mathrm{Fe}_{16} \mathrm{~N}_{2}(\alpha)$ is formed at lower temperatures and its orientation is dependent on the $\alpha$ matrix, and the second $\mathrm{Fe}_{4} \mathrm{~N}\left(\gamma^{\prime}\right)$ at higher temperatures $\left(>200{ }^{\circ} \mathrm{C}\right)$ is characterized by larger dimensions and unspecified orientation in the matrix [1-5].

The described aging modes lead to a decrease in the strength of the satiated nitric ferrite and are not able to use the strengthening potential of the hardened state of the ferrite phase [1-5].

It is obvious that at the basis of these substructural changes of the ferrite phase lies the release of $\alpha^{\prime \prime}$ - nitride $\left(\mathrm{Fe}_{16} \mathrm{~N}_{2}\right)$ and the rupture of its coherent connection to the matrix [6-8].
The $\alpha^{\prime \prime}$ - phase has a multi-atomic large crystal cell with parameters $\mathrm{a}=5.72 \AA$ and $\mathrm{c}=6.29 \AA[6-$ $10]$, which coherently interacts with the body-centred cubic unit cell of the ferrite along the plane (100) [68].

During slow cooling after gas carbonitriding in the diffusion zone, the ferrite crystals release the nitrogen dissolved in them until reaching an equilibrium along the saturation line changing the concentration of $0.11 \div 0.01 \%$. The nitrogen released is in the form of $\gamma^{\prime}$ nitride, which constitutes an independent phase and follows the reaction $\alpha \mathrm{N} \rightarrow \alpha \mathrm{N}+\gamma^{\prime}$. The shape in which the $\gamma^{\prime}$ is observed is needle-like and equiaxed in the ferrite crystals. On cooling in environments where the period after gas carbonitriding is insufficient for secondary releases, a supersaturated $\alpha \mathrm{N}$ solid solution is formed in the diffusion zone. The soluble component is dissolved in the octahedral cavities of the body-centred cubic unit cell, fills the point defects in the structure (vacancies), and groups around the dislocation nodes as well. This requires the cooling of the test samples to be carried out in water [9-15].

Reheating activates the dissolved nitrogen and the system's tendency to minimize the amount of free energy leads to its more favourable arrangement, 
bringing the structure to a more equilibrium state. The changes occurring in the structure during reheating may be recorded:

- Changes in the integral area of the X-ray line, as a consequence of structural micro tensions (II genus), defects in the arrangement, blockage in the crystal.

- Changes in the mechanical characteristics (hardness, strength).

- Microstructural changes - decoration of the ferrite crystals with subsequent secondary separation is registered.

The purpose of the study is to determine the possibility for strengthening the diffusion zone after reheating the carbonitriding iron materials with ferrite structure, and to identify optimal technological modes after reheating, gas carbonitriding temperature, heating temperature $-t_{\text {aging }}$, reheating time $-\tau_{\text {aging }}$.

\section{Experimental study}

\subsection{Preparation of experiment samples}

The tests were carried out on cut samples of technically pure iron (Armco) [18-20] measuring $40 \times 15 \times 2 \mathrm{~mm}$. The samples are deformed by a tensile test machine with a deformation rate of $\varepsilon=16 \%$, and then re-crystallisation heated at $700{ }^{\circ} \mathrm{C}$ for 2 hours, achieving a large-grain ferrite structure with an average ferrite grain size $\overline{\mathrm{I}}=105 \mu \mathrm{m}$. Nitric ferrite is obtained after gas carbonitriding in the following mode:

- low temperature saturation:

$$
\begin{gathered}
\mathrm{t}=570^{\circ} \mathrm{C}, \\
\frac{N H_{3}}{\mathrm{CO}_{2}}=\frac{1500_{h}^{l}}{200_{h}^{l}}, \\
\tau=3 \mathrm{~h}
\end{gathered}
$$

- cooling in water.

The hardening of the samples is carried out in water and after that they are stored in a refrigeration chamber. Since on the surface of the samples there is a carbonitride zone consisting of $\varepsilon$-carbonitride, this layer is removed by electrochemical corrosion to allow for conducting X-ray structural studies of the ferrite phase. The aging is carried out in a laboratory chamber furnace with a fan for effecting convective heat exchange within the volume of the chamber.

Table 1 shows the aging regimes studied and Fig. 1 illustrates the thermal treatment cyclorama of the samples.

Table 1. The aging regimes

\begin{tabular}{ccccccccccc}
\hline $\mathbf{T}$ & \multicolumn{10}{c}{ Heating time, min } \\
\hline${ }^{\circ} \mathrm{C}$ & 5 & 10 & 20 & 40 & 60 & 90 & 120 & 140 & 180 & 400 \\
\hline 60 & $*$ & & $*$ & $*$ & $*$ & & $*$ & $*$ & $*$ & $*$ \\
\hline 80 & $*$ & & $*$ & $*$ & $*$ & $*$ & $*$ & $*$ & $*$ & $*$ \\
\hline 100 & & $*$ & $*$ & $*$ & $*$ & & $*$ & $*$ & $*$ & $*$ \\
\hline
\end{tabular}

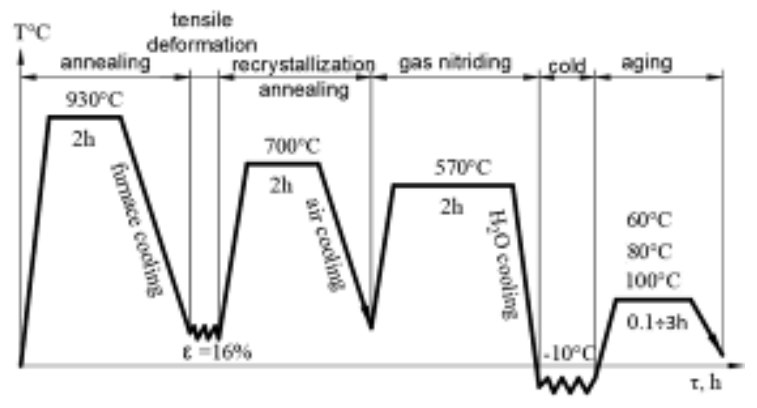

Fig. 1. The thermal treatment cyclorama of the samples

\subsection{Methodology of metallographic tests and $X$ - ray diffraction analysis}

The determination of the crystals size in the different technological modes is carried out using a specialized "Epiquant" metallographic microscope.
The experiments are conducted using standard metallographic methods to monitor thin gradient layers. The transverse surface of the sample is observed, with the sample pressed with metal clamps and thin foil placed on the frontal surfaces. The purpose of the observation is to trace the secondary release on the cut ferrite grains. For this purpose, a polarized light observation methodology is used. Fine dispersion releases require greater optical magnification, which necessitates the use of immersion optics.

A standard methodology for an X-ray graphic recording is applied to perform the $\mathrm{X}$-ray analysis using the U.S.-50IM device. The set does not allow digital capture of the profile obtained. This requires the use of the graphical programming product "Bytescout Graph Digitizer Scout" enabling the conversion of graphical results into digital Fig. 2. The graphs corresponding to the other aging temperatures are constructed in the same way. 


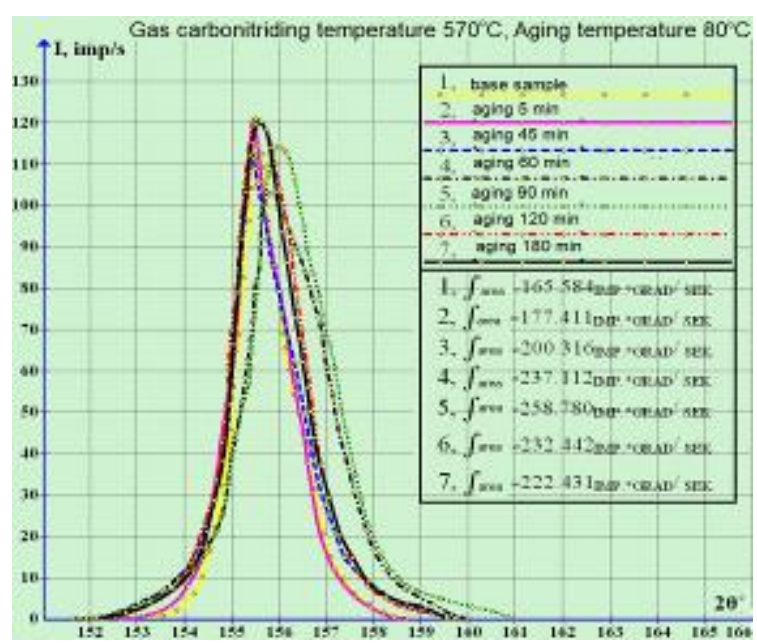

Fig. 2. Areas of X-ray lines (211) in nitrogen ferrite after gas carbonitriding at $570{ }^{\circ} \mathrm{C}$ and aging at $80^{\circ} \mathrm{C}$

\section{Results of the experimental study}

The article does not address issues related to the mechanism of aging, but it sets out the results of the kinetic changes of the X-ray broadening of the lines of the diffraction maximums of ferrite, as well as the micro-hardness.

\subsection{Results of metallographic tests}

At high temperature $\left(100{ }^{\circ} \mathrm{C}\right)$ and duration of aging, a characteristic emphasis on the relief of the ferrite structure is noted, evenly the entire volume of grains observed by special metallographic methods (immersion optics, interfering contrast and polarization) Fig. 3.

Figure $3 \mathrm{a}, \mathrm{b}$ shows the initial structures after gas carbonitriding. The difference between the two samples refers to the manner of cooling (fast and slow). With slow cooling, the system is in equilibrium throughout the whole cooling period, accompanied by the release of the $\gamma^{\prime}$ phase and thus maintaining an equilibrium concentration of the basic matrix $\alpha \mathrm{N}$. The release has a needle-like form. The stable $\gamma$ '-phase $\mathrm{Fe}_{4} \mathrm{~N}$ cumulates on the plane (012) of the matrix and arranges at an acute angle.

In the microstructure characterized by its nonequilibrium state, Fig. 3a, resulting from the high cooling rate and the formation of a supersaturated solid solution, the crystals are visibly homogeneous, with no apparent relief.

Most of the studies of nitrogen ferrite have been performed at aging temperatures of above $100{ }^{\circ} \mathrm{C}$, at which significant phase changes take place. These phase changes consist in the continuous release of iron nitrides of the type $\mathrm{Fe}_{16} \mathrm{~N}_{2}\left(\alpha^{\prime \prime}\right)$ and $\mathrm{Fe}_{4} \mathrm{~N}\left(\gamma^{\prime}\right)$.
The former is formed at lower temperatures and is orientation dependent on the $\alpha$-matrix, and the latter is formed at higher temperatures $\left(>200{ }^{\circ} \mathrm{C}\right)$, and is characterized by its larger dimensions and indeterminate orientation in the matrix.

These aging modes lead to a continuous loss of strength (softening) of the supersaturated nitrogen ferrite and are not able to make use of the hardening potential, which is generally contained in the hardened state of the ferrite phase.

The decomposition of $\alpha$ saturated solid solution follows the general laws of phase transformations. Initially, at low aging temperatures, Cottrell atmospheres are formed. As the retention time increases (temperature rise to $60 \div 150{ }^{\circ} \mathrm{C}$ ), lamellar microstructures of the metastable $\alpha$ " - $\mathrm{Fe}_{16} \mathrm{~N}_{2}$ phase are developed, coherently connected to the matrix. Upon the release of the metastable $\mathrm{Fe}_{16} \mathrm{~N}_{2}$ nitride, a pronounced predominant orientation of its lamellae in the direction of plane (100) of the original nitrogen ferrite lattice is observed. In the initial stage of aging, the length of the lamellar microstructures is 100-200 $\AA$ and increases in the aging process to $500-5000 \AA$. Due to the obviously small size and the lack of boundaries in the individual zones formation, Fig. 3c, $\mathrm{d}$, e, they cannot be observed as defined needle-like crystals, but only as matrix $\alpha \mathrm{N}$ relief.

Upon breaking the coherent bond with the main matrix, the precipitates are observed as needle-like crystals, similar to the slowly cooled structures, Fig. 3 b.

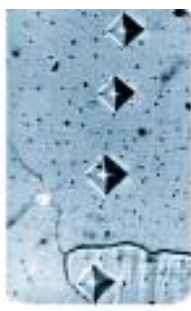

a

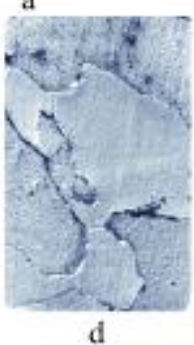

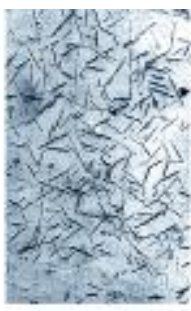

b
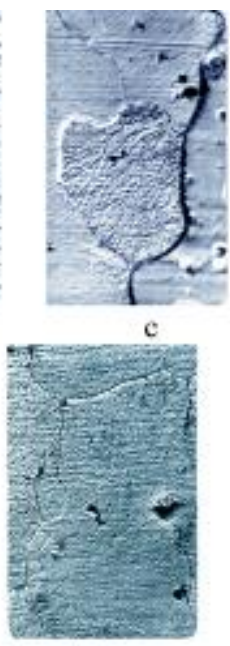

Fig. 3. Microstructure in the diffusion zone after gas carbonitriding, $t=570^{\circ} \mathrm{C}, \tau=3 \mathrm{~h} \times 500$

a/ gas carbonitriding $\rightarrow$ cooling in $\mathrm{H}_{2} \mathrm{O}$,

b/ gas carbonitriding $\rightarrow$ slowly cooled,

c/ gas carbonitriding $\rightarrow$ cooling in $\mathrm{H}_{2} \mathrm{O} \rightarrow t_{\text {aging }}=80$ ${ }^{\circ} \mathrm{C}, \tau_{\text {aging }}=60 \mathrm{~min}$, 

$d /$ gas carbonitriding $\rightarrow$ cooling in $\mathrm{H}_{2} \mathrm{O} \rightarrow t_{\text {aging }}=80$
${ }^{\circ} \mathrm{C}, \tau_{\text {aging }}=120 \mathrm{~min}$,

e/ gas carbonitriding $\rightarrow$ cooling in $\mathrm{H}_{2} \mathrm{O} \rightarrow t_{\text {aging }}=$ $100^{\circ} \mathrm{C}, \tau_{\text {aging }}=60 \mathrm{~min}$

\section{2. $X$ - ray diffraction analysis}

X-ray examinations were carried out of the line (211) of nitrogen ferrite, which is a major phase in the diffusion zone. The main data that can be obtained from the X-ray structural analysis is a study of the zones of nitrogen atoms formed in the ferrite matrix, leading to the deformation of one of the atomic planes of the solvent. This type of micro tensions of the crystal cell can be determined by changing the width of the X-ray line. Table 2 presents the results obtained from the X-ray lines filmed (211) of the $\alpha \mathrm{N}$ phase and the specified integral areas for the different aging modes.

The results of the X-ray examinations are illustrated in Table 2, from which it appears that all the three output samples have different integral areas. Therefore, analyses based on absolute values are not entirely reliable.

Real analyses are obtained using relative values (1). When using relative values, for the integrated area we use $\int_{\mathrm{i}, \mathrm{j}}$. Index (i) means $\mathrm{t}_{\text {aging }},{ }^{\circ} \mathrm{C}$; j means $\tau_{\text {aging, }}$ min.

$$
\int i, j(\text { relative })=\frac{\int \text { base sample }-\int i_{, j}}{\int \text { base sampe }}
$$

Table 2. Integral area of the $X$-ray line (211)

\begin{tabular}{cccc}
\hline \multicolumn{2}{c}{ Time aging } & \multicolumn{2}{c}{$\mathbf{T}^{\circ} \mathbf{C}$ aging } \\
\hline $\boldsymbol{\tau}_{\min }$ & $\boldsymbol{\tau}=\mathbf{6 0}^{\circ} \mathbf{C}$ & $\boldsymbol{\tau}=\mathbf{8 0}^{\circ} \mathbf{C}$ & $\boldsymbol{\tau}=\mathbf{1 0 0}{ }^{\circ} \mathbf{C}$ \\
\hline base sample & 207.524 & 165.584 & 188.685 \\
\hline 5 & 213.045 & 177.411 & \\
\hline 10 & & & 189.599 \\
\hline 20 & 217.995 & 200.316 & 190.497 \\
\hline 40 & 220.137 & 237.112 & 197.993 \\
\hline 60 & 228.643 & 258.780 & 200.218 \\
\hline 90 & & 232.442 & \\
\hline 120 & 228.952 & 222.431 & 167.421 \\
\hline 180 & 231.164 & 200.316 & 164.231 \\
\hline 400 & 188.810 & 184.216 & 158.349 \\
\hline (I, imp/sek) in nitride ferrite tgcn $_{\text {gcn }}=570^{\circ} \mathrm{C}$
\end{tabular}

Fig. 4 indicates that the maximum value of the integral area in the $\alpha \mathrm{N}$ phase aging is observed at an aging temperature of about $80{ }^{\circ} \mathrm{C}$ and time $\tau_{\text {aging }}=$ $90 \div 120$ min.

Fig. 4 combines the results of the radiographs for all temperatures and aging times.

Where the red region of isolines shows the extremum of the relative value of the X-ray line widening calculated by formula 1 according to the technological parameters of time and temperature set. The absolute broadening of the baseline (Fig. 2 sample 1) is taken account of in the calculations of the relative values of all X-ray lines.

As the time and temperature of the aging increase, we can note a decrease in the area of the Xray line. Perhaps this is due to the system need to move to a more equilibrium state, which is characterized by a partial rupture of the coherent link between the matrix $(\alpha \mathrm{N})$ and the zone of dissolved nitrogen atoms formed in the aging process. The aspiration is to build a new $\gamma^{\prime}$ phase through raising the temperature. The studies performed proved a certain instability of this coherence, that is, it occurs under strictly defined conditions and is quickly destroyed. Perhaps this is due to the small similarity of the crystal grids of $\alpha^{\prime \prime}$ and $\alpha$ phases, the difference in concentrations and similarity of the cell of $\alpha^{\prime \prime}$ and $\gamma^{\prime}$ - nitrite, which determines the rapid transition of $\alpha^{\prime \prime}$ to $\gamma^{\prime}$-nitrite. The strictly plastic shape and orientation of the $\alpha^{\prime \prime}$-crystals, which are particularly well manifested in aging above $180{ }^{\circ} \mathrm{C}$, confirm this crystallographic difference between $\alpha$ " and $\alpha$ - phases.

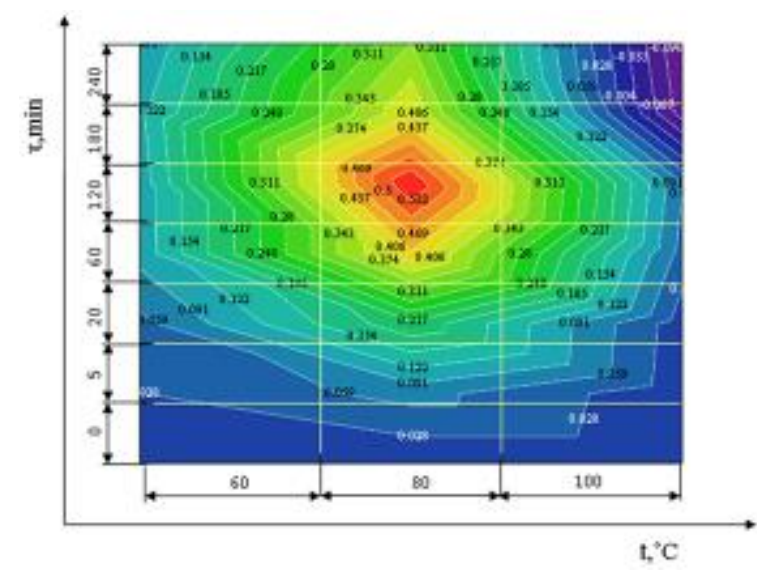

Fig. 4. Change in the relative integral area of the X-ray line (211) at an, depending on the temperature $\left(570^{\circ} \mathrm{C}\right)$ and aging time at gas carbonitriding

\subsection{Microhardness tests}

As a result of the aging deformation of the crystal lattice, which is evident from the X-ray line broadening Fig. 4, a change in the microhardness Fig. 5 , also occurs, which is indicative of the overall change in the mechanical properties in the diffusion region [16-19].

The results obtained are used for the determination of the change in microhardness with the change in the technological parameters temperature and aging time, Fig. 5. The maximum 
hardness of $470 \mathrm{HV}$ recorded along the blue line corresponds to an aging mode of $\mathrm{t}=80^{\circ} \mathrm{C}$ and $\tau=90$ min, which is associated with the reported line broadening extremum in Fig. 4. For comparison, the initial hardness in the diffusion zone of nitrogen ferrite is in the range of 250-320 HV [16-19].

The elastic deformation of the ferrite matrix cell, as indicated by the increased X-ray broadening, is the cause for an increase in the hardness of the aging matrix. This change in the hardness of the nitrogen ferrite in the aging process, shown in Fig. 5, is consistent with the variation of the X-ray broadening. It is notable that the initial state of the different samples is characterized by different hardness. This difference is due to the fact that each sample has a certain gradient of nitrogen concentration, and respectively of nitrogen ferrite concentration, in the diffusion layer. Although hardness is determined at the same distance from the surface $(40 \mu \mathrm{m})$ for all samples, some deviation in the degree of saturation of the individual samples can be expected. In addition, the change in micro hardness is measured in separate ferrite grains, therefore it is possible that the crystallographic orientation may also have a certain influence.

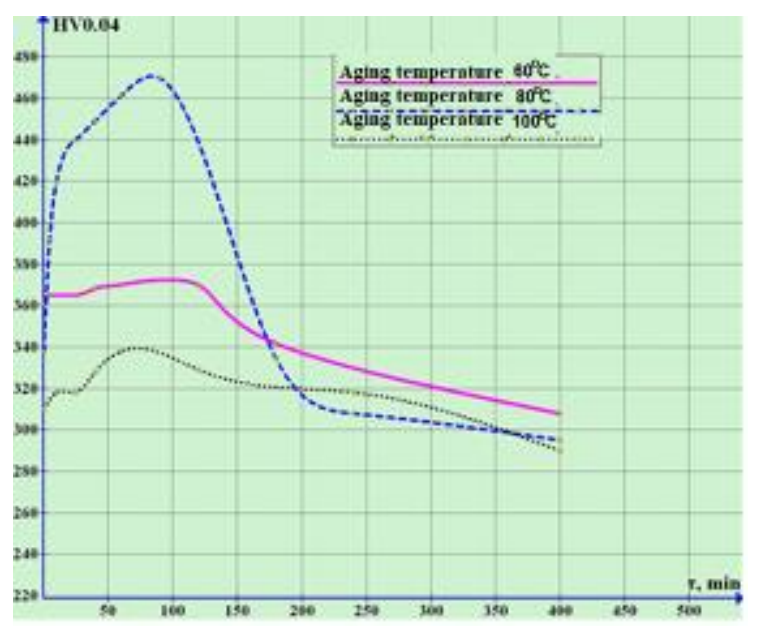

Fig. 5. Microhardness at constant depth in the diffusion zone after gas carbonitriding at $t=570$

${ }^{o} \mathrm{C}$, depending on temperature and aging time

A similar effect is perceived in the determination and analysis of X-ray broadening. Notwithstanding these initial deviations, a maximum in hardness is obviously observed in the aging process, undoubtedly indicating an increase in the strength of nitric ferrite after aging in a narrow temperature range of $80-90{ }^{\circ} \mathrm{C}$. At lower temperatures, the activation of nitrogen atoms in the saturated ferrite is still insufficient for their segregation and the formation of corresponding precipitates. Deviations in X-ray broadening and hardness after aging at $60{ }^{\circ} \mathrm{C}$ are negligible. Aging at $100{ }^{\circ} \mathrm{C}$ also has a strengthening effect, but not as pronounced as after aging at $80{ }^{\circ} \mathrm{C}$. The maximums for these temperatures are drawn towards smaller durations (times), which is natural due to the greater diffusion mobility of nitrogen atoms in ferrites.

\section{Conclusion}

In conclusion, it should be noted that the saturated nitrogen ferrite formed has a tendency to age after low temperature gas carbonitriding, its strength indicating the greater increase in a temperature range of $80-90{ }^{\circ} \mathrm{C}(470 \mathrm{HV})$ when retained at these temperatures from 40 to 70 minutes. For aging processes, these optimal temperature ranges and aging time turn out to be too narrow, due to the high sensitivity of the coherent interaction between the nitride phase $\left(\alpha^{\prime \prime}\right)$ and the ferrite matrix $(\alpha)$.

\section{References}

[1]. Bielawski J., Baranowska J., Szczecinski K., Protective Nitrided Layers on Ferite-Austenite Chromiun Steel, Materials Science, vol. 11, no. 3, p. 221-225, 2005.

[2]. Callister W. D., Materials Science and Engineering: An Introduction, $7^{\text {th }}$ ed., John Wiley \& Sons, Inc., United States of America, 2007.

[3]. Christiansen T., Somers M. A. J., Characterisation of Low Temperature Surface Hardened Stainless Steel, Struers Journal of Materialography, p. 2-17, 9/2006.

[4]. Grachov S. V., Baras V. R., Thermomechanical treatment of age hardening austenitic steels, Ind. Heat., vol. 47, no. 10, p. 2023, 1980.

[5]. Kubota S., Xia Y., Tomota Y., Work-hardening Behavior and Evolution of Dislocation-microstructures in High-nitrogen Bearing Austenitic Steels, ISIJ International, 38(5), 474, 1998.

[6]. Llewellyn D. T., Hudd R. C., Steels: Metallurgy and applications, $3^{\text {rd }}$ Edition, Butterworth-Heinemann, 400, 1998.

[7]. ***, Handbook: Steel and alloys grades and properties, http://www.steelnumber.com/en/steel_composition_eu.php?name_i $\mathrm{d}=18$.

[8]. Marchev K., Landis M., Valletio R., Cooper C. V., Giessen B. C., The $m$ - Phase Layer on Ion-Nitrided Austenitic Stainless Steel (III) An Expitaxial Relationship Between the $m$-Phase and the $\gamma$ Parent Phase and a Review the $m-$ Phase and the $\gamma$ Parent Phase and a Review of Structural Identifications of This Phase, Surface and Coatings Technology, 116-119, p. 184-188, 1999.

[9]. Peralta P. D., Dislocation structure and cyclic plasticity, Encycl. Mater. Sci. Technol., Elsevier, p. 2222-2235, 2001.

[10]. Podgomik B., Vizintin J., Ronkainen H., Holmberg K., Friction and Wear Properties of DLC-coated Plasma Nitrided Steel in Unidirectional and reciprocating Sliding, Thin Solid Films 377-378, p. 254-260, 2000.

[11]. Podgornik B., Vizintin J., Wanstrand O., Larsson M., Hogmark S., Ronkainen H., Holmberg K., Tribological Properties of Plasma Nitrided and Hard Coated AISI 4140 Steel, Wear, 249, p. 254-259, 2001.

[12]. Sun Y., Li X., Bel T., Structural Characteristics of Low Temperature Plasma Carburised Austenitic Stainless Steel, Materials Science and Technology, vol. 15, p. 1171-1178, October 1999.

[13]. Haasen P., Physical metallurgy. Cambridge, New York: Cambridge University Press, 1978. 


\section{THE ANNALS OF “DUNAREA DE JOS" UNIVERSITY OF GALATI \\ FASCICLE IX. METALLURGY AND MATERIALS SCIENCE \\ №. 1 - 2021, ISSN 2668-4748; e-ISSN 2668-4756 \\ Article DOI: https://doi.org/10.35219/mms.2021.1.04}

[14]. Samuel J., Introduction to materials science course manual, Madison, Wisconsin: University of Wisconsin-Madison, 2009.

[15]. Leslie W. C., The physical metallurgy of steels, Washington: Hempisphere Pub. Corp., New York: McGraw-Hill, ISBN 0070377804, 1981.

[16]. Chinn R. L., Hardness, bearings, and the Rockwells, Advanced Materials \& Processes, 167 (10), p. 29-31, 2009.
[17]. Davis J. R., Surface hardening of steels: Understanding the basics, Materials Park, OH: ASM International, 2002.

[18]. Dieter George E., Mechanical Metallurgy, SI Metric Adaptation, Maidenhead, UK: McGraw-Hill Education, ISBN 007-100406-8, 1989.

[19]. Revankar G., Introduction to hardness testing, Mechanical testing and evaluation, ASM Online, vol. 8, 2003. 